\section{LA INDUSTRIA DEL CINE EN COLOMBIA. \\ Entre el optimismo ingenuo y el pesimismo crónico}

\section{FILM INDUSTRY IN COLOMBIA . Between the naive optimism and the chronic pessimism}

Guillermo Alejandro D’abbraccio Krentzer*

\section{RESUMEN}

La industria cultural es un renglón clave en las economías capitalistas aporta al Producto Interno Bruto de los países en desarrollo, contribuye en la formación de recursos humanos cualificados, la configuración de las identidades nacionales, la consolidación del consumo cultural, la formación de audiencias y públicos críticos. El conjunto de los países desarrollados, con menos del $30 \%$ de la población mundial, concentran el $87 \%$ de las salas cinematográficas y el $54 \%$ de las radioemisoras existentes en cambio los países en desarrollo, con más del $70 \%$ de la población, sólo poseen el $13 \%$ de las salas y el $46 \%$ de las emisoras radiales. De modo que es pertinente interrogarse por las posibilidades de América Latina y, en particular de Colombia, de hacer parte efectiva de un mercado de bienes y servicios de la industria cultural, especialmente del cine, en la era de la globalización.

En la perspectiva optimista, la producción de cine en colombiana ha ascendido desde la ley de cine de 2003, se han realizado diferentes cintas (cortos y largometrajes) que han despertado el interés del público local como fue el caso de "Soñar no cuesta nada" de Rodrigo Triana o "El colombian dream" de Felipe Aljure 'Perder es cuestión de método', de Sergio Cabrera y 'La sombra del caminante', de Ciro Guerra. Sigue siendo problema la exhibición, la internacionalización, la formación de guionistas, la formación de público, y el acompañamiento a quienes reciben el apoyo financiero para las producciones.

Palabras claves: Ley de cine, Colombia, cine, entretenimiento, industria cultural

Recibido: Julio 2, 2015 - Aceptado: Julio 10, 2015

\section{SUMMARY}

Cultural industry is a key line in capitalist economies; it contributes to the gross domestic product of developing countries, training of qualified human resources, national identities configuration of cultural consumption, and construction of criticism sense in audience. The whole group of developed countries, with less than $30 \%$ of world's population, concentrates $87 \%$ of the cinemas and $54 \%$ of existing radio stations; on the opposite of developing countries, with over $70 \%$ of the population, but they only count with $13 \%$ of cinemas and $46 \%$ of radio stations. Therefore it is pertinent to question the possibilities of Latin America, particularly Colombia, in making effective part of a market for goods and service, especially films, in the cultural industry in the era of globalization.

From an optimistic view, film production in Colombia has risen from the 200 Film Law. Different productions (short films and feature films) have caught the eye of local audience, as was the case of "Soñar no cuesta nada" by Rodrigo Triana or "El colombian dream" by Felipe Aljure," Perder es cuestion de metodo" by Sergio Cabrera and "La sombra de caminante" by Ciro Guerra. Significant issues to resolve such as internationalization, training of screenwriters, audience education, and financial support for movie makers still remain.

Keywords: Film Law, Colombia, cinema, entertainment, cultural industry

Received: July 2, 2015 - Accepted: July 10, 2015

*Politólogo y Comunicador social de la Universidad de Buenos Aires (UBA, Argentina, 1993 y 1995 respectivamente); Especialista en Antropología jurídica de la Universidad del Cauca; Magíster en Comunicación y Doctor en Ciencias Sociales de la FLACSO (México). Profesor visitante en universidades de América Latina y Europa. Investiga dor Senior de Colciencias. Miembro de Redes como Relaju (Red latinoamericana de Antropología jurídica); GT CLACSO "Ser indigena urbano hoy"; ACICOM, ALAIC, IPSA (International Political Science Association). Fue profesor de las Universidades del Cauca y de Manizales. Desde el año 2001 es profesor Asociado de la Universidad Nacional de Colombia. Email: gadabbracciok@unal.edu.co 


\section{INTRODUCCIÓN}

¿Por qué es pertinente el estudio de la industria cinematográfica? Y en especial, ¿Por qué en un país del denominado "Tercer Mundo"? Pues porque la industria cultural es un renglón clave en las economías capitalistas (Ortiz: 1997:31), un aporte fundamental en los PIB de los países en desarrollo, una contribución en la formación de recursos humanos cualificados, configuración de las identidades nacionales, consolidación del consumo cultural y formación de audiencias y públicos críticos [1].

Se sabe que la importancia de la industria cinematográfica no radica solamente en miles de millones de dólares que moviliza la producción y la comercialización de películas y programas televisivos. Para los EE.UU. representa más de 50 mil millones de dólares por año, según el estudio de W.B Beyers "Culture, services and regional development" (2002:14). Pero además trae por sí mismo las posibilidades del lenguaje audiovisual, por sus características "palimpsésticas", para inducir, junto a la incentivación del consumo, ideas y valores que subyacen en imágenes $y$ sonido (Cicchetti: 2003: 65).

Y si giramos la mirada a nuestros lares, sobre todo antes de la ley del cine de 2003 ¿Cuál era la situación actual de la industria del cine? Los datos más recientes sobre el sector cinematográfico en Colombia se encuentran consignados en el estudio evaluativo realizado por el Ministerio de Cultura y el Fondo Mixto de Promoción Cinematográfica durante el año 2000, a través de Fedesarrollo. En éste se examinó el impacto del sector cinematográfico sobre la economía colombiana, analizando la cadena cinematográfica, integrada por productores, distribuidores y exhibidores. Las cifras del estudio revelaron que la industria cinematográfica colombiana ocupó en promedio algo más de 6.600 personas en 1993, alrededor de 5.000 en 1994, cerca de 3.000 en 1995, y entre
2.400 y 2.700 en los demás años de la década, siendo la exhibición la que genera la mayor parte del empleo en la industria, con porcentajes que van entre $80 \%$ y $90 \%$ (Fedesarrollo:2000:9)

El panorama siempre ha sido desolador, ya que la cinematografía colombiana cuenta con apenas un historial de solo 214 largometrajes, y aunque se ha mostrado una tendencia a la baja, pasando de nueve filmes anuales en promedio para los años 1981 - 1985 a 1,5 en promedio en los años 1991 - 1995, se evidencia una recuperación a cuatro filmes promedio producidos entre 1996 y 1999 (Fedesarrollo: 2000). En lo que respecta a la fase de distribución, como ocurre internacionalmente, ésta se encuentra bastante concentrada. Las cuatro empresas de mayor participación en el mercado distribuyeron en 1998 el 96\% del número total de películas. A partir de la promulgación de la nueva ley de cine en Colombia en 2003, se procura afianzar el objetivo de promover la actividad cinematográfica.

Es por ello que la industria cinematográfica designa los momentos y actividades de producción de bienes y servicios en esta órbita audiovisual, en especial producción, distribución o comercialización y exhibición. Por su parte, el concepto de cinematografía nacional comprende el conjunto de acciones públicas y privadas que se interrelacionan para gestar el desarrollo artístico e industrial de la creación y producción audiovisual y de cine nacionales y arraigar esta producción en el querer nacional, a la vez apoyando su mayor realización, conservándolas, preservándolas y divulgándolas (Safir: 2004: 59; Cedem: 2001: 11).

\section{En la actualidad, América Latina y el Caribe} ocupan menos del $40 \%$ del espacio que tenían en las exportaciones mundiales de $1950 \mathrm{y}$, en lo que respecta a la situación de sus Industrias Culturales (Getino:2008:4), pero particularmente, al desarrollo de las nuevas tecnologías de información y comunicación -tecnologías 
comunicacionales de punta-, las cifras plantean un pobre panorama que, paradójicamente, no concuerda con las potencialidades de la región. Sin embargo, el panorama de América Latina para la década de los noventa, se caracterizó por estar sufriendo modificaciones traducido en la apertura de mercados a la participación de inversionistas privados y desregulación de sectores básicos de la industria y los servicios que buscan incrementar la productividad y la eficiencia, pero, sobre todo, llevarlos a la mayoría de la población.

El conjunto de los países desarrollados, con menos del $30 \%$ de la población mundial, concentran el $87 \%$ de las salas cinematográficas $y$ el $54 \%$ de las radioemisoras existentes. Los países en desarrollo, con más del $70 \%$ de la población, sólo poseen el $13 \%$ de las salas y el $46 \%$ de las emisoras radiales. De modo que valdría la pena interrogarse acerca de cuáles son las posibilidades de América Latina $y$, en particular de Colombia, de hacer parte efectiva de un mercado de bienes y servicios de la industria cultural en la era de la globalización .

Siendo escenarios diferenciados, y con menor peso económico que el contexto estadounidense, la industria audiovisual europea emplea aproximadamente 1,8 millones de personas (Comisión Europea: 2005: 96) y dispone del mercado audiovisual más importante del mundo con 370 millones de consumidores. Por otro lado, las cien primeras grandes empresas audiovisuales en Europa tienen un volumen anual de 7.000 millones de dólares con un crecimiento anual del 15\% desde 1999 (O'Connor:1999)

Al respecto, es pertinente observar la situación española. El aporte de las actividades culturales al Producto Interior Bruto (PIB) español ronda el $3 \%$. Si se añaden otras actividades vinculadas a la cultura, como diseño, publicidad y otras conexas, se elevaría al $4 \%$, según el avance de la Cuenta Satélite de la Cultura, que mide el impacto económico de este sector en el conjunto de la economía española a través de indicadores económicos oficiales. El porcentaje, que ha venido oscilando entre $3 \%$ y $3,2 \%$ a lo largo de la última década, supone una cifra cercana a 32.000 millones de euros. En términos macrosectoriales, el PIB cultural tiene un peso relativo superior al energético $(2,7 \%)$ y similar al agrario $(3,7 \%)$. El empleo generado por la industria cultural se sitúa encima de 562.000, según datos de 2012. Según datos de Cultura, la crisis apenas afectó al sector. En 2012 el empleo era de 397.600 personas. El nivel educacional de los empleados es alto, con un $50 \%$ de universitarios y $44 \%$ con educación secundaria.

En nuestro vecindario, Latinoamérica, es posible percibir que los tiempos cambian también, aunque lentamente, pero la conciencia está emergiendo en sectores políticos y empresariales

La industria del cine en México constituye uno de los referentes en cuanto atañe a planeación, capacidad de organización y un público que se destaca en la región. Es pertinente señalar la creación de Procine DF (Ciudad de México), un fideicomiso a la producción; de una red de salas que llega a un número considerable de cincuenta con precios accesibles al gran público. Esta red será dedicada a la exhibición de cine mexicano principalmente, y cine internacional no estadounidense. Las películas mexicanas podrán permanecer en cartelera hasta 10 semanas. De igual manera, la nueva Ley de Fomento al Cine brinda apoyo a diversos eventos de exhibición, como el foro de la Muestra Internacional de Cine, la Muestra de Cine Ambulante, el DOCSDF o el Festival de Cine Latinoamericano.

En Argentina el Fondo de Fomento Cinematográfico del Instituto Nacional de Cine y Artes Audiovisuales se creó en 1997 a partir de un impuesto equivalente al $10 \%$ aplicable sobre el 
precio básico de toda localidad o boleto entregado gratuita $u$ onerosamente para presenciar espectáculos cinematográficos en todo el país cualquiera sea el ámbito donde se realicen. El impuesto recae sobre los espectadores, y los empresarios o entidades exhibidoras adicionarán este impuesto al precio básico de cada localidad.

La industria cinematográfica de Brasil ha pasado por períodos de auge y declive, un reflejo de su dependencia del financiamiento e incentivos estatales. El gobierno brasileño decidió inyectar vida nueva en la industria nacional de cine en 2002 a través de una ley federal que permite al inversor extranjero adquirir participaciones en las películas brasileñas. Todo el mercado brasileño está en manos de la ley audiovisual del gobierno. Productoras de todos los tamaños salen en busca de un guion y envían al gobierno con solicitud de financiación. Los inversores privados están protegidos en gran medida de las pérdidas derivadas de un posible fracaso en las pantallas, ya que el gobierno paga buena parte de la cuenta. Críticos afirman que Brasil tiene un modelo similar al europeo, bajo el capricho de los directores, a diferencia del modelo americano preocupado en la rentabilidad

\section{EL CINE COLOMBIANO: MÁS ALLÁ DEL "OPTIMISMO" INSTITUCIONAL}

A lo largo de su corta historia, el cine colombiano no ha logrado ser rentable como industria, y por ello en la investigación realizada nos preguntamos por la configuración de una verdadera industria cultural, en este caso cinematográfica. Todo este panorama ha obstaculizado su continuidad en la producción y en el empleo de realizadores y técnicos. En el inicio del siglo XX existieron algunas compañías que intentaron mantener un nivel constante de producción, pero las carencias de capitales de inversión unido a la fuerte competencia (y experiencia) extranjera terminaron por derrumbar a los más optimistas de ese entonces. En los años 1980 la recién creada FOCINE permitió que se realizaran algunas producciones. Sin embargo, la liquidaron en corto tiempo.

Con la ley de cine de 2003, el cine colombiano tomó un nuevo aire, pues se incrementó levemente la producción nacional. En estos 13 años de existencia de la nueva Ley del cine colombiano, se han realizado diferentes cintas (cortos y largometrajes) que han despertado el interés del público local como fue el caso de "Soñar no cuesta nada" de Rodrigo Triana, (me refiero a taquilla y no a su dudosa calidad estética o nula circulación en festivales), producción que alcanzó cerca de un millón doscientos mil espectadores o "El colombian dream" de Felipe Aljure que destacó por sus innovaciones técnicas y narrativas nunca antes vistas en el cine colombiano. Algunos exageradamente optimistas han llegado a considerar este periodo como el renacimiento del cine colombiano. Los pesimistas, en cambio, señalan que falta apoyo en la exhibición, comercialización y especialmente formación de públicos.

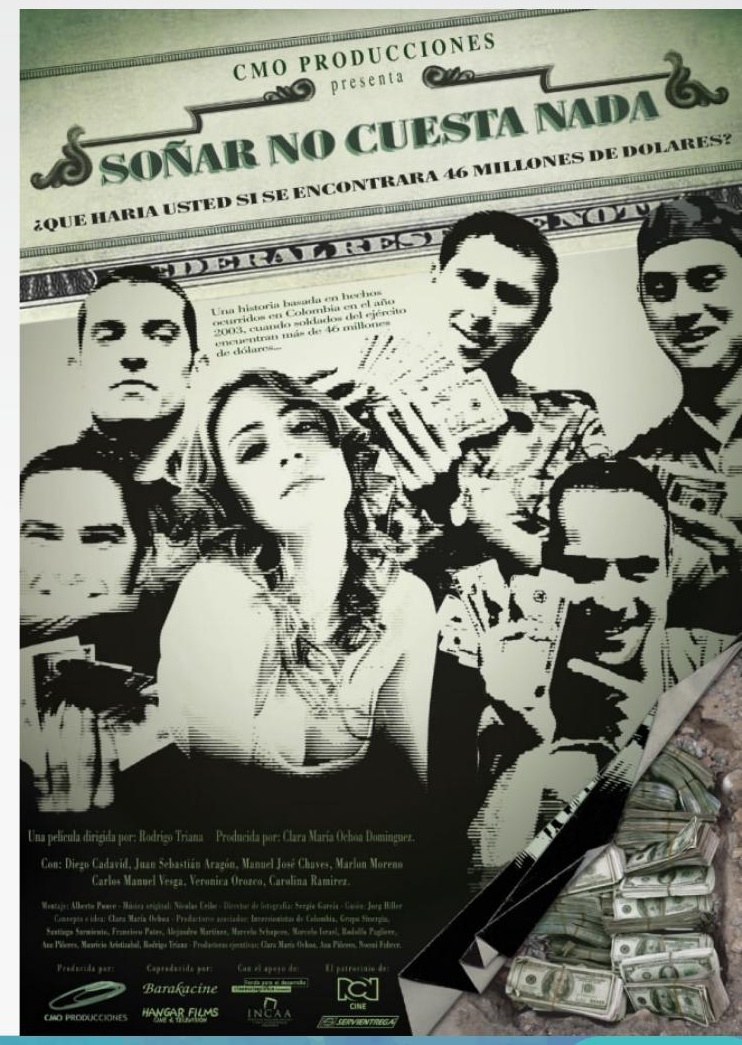


Una rigurosa investigación de Fedesarrollo de 2002, puso en cifras la realidad de la industria cinematográfica colombiana, evidenciando el escaso peso dentro del conjunto de la economía y destacando el sector de la producción como el más débil de las tres instancias de la cadena, imaginando escenarios concretos para el funcionamiento de la industria (número de películas nacionales al año, promedio de asistencia requerida, etc). Durante los primeros seis años de vigencia de la ley, fueron estrenados 52 largometrajes, en promedio ocho anuales, y se pasó de una inversión total de 50 millones en 2003 a 30 mil millones en el 2008, según cifras de la Dirección de Cinematografía

La siguiente tabla presenta las estadísticas comparativas de los estrenos del cine nacional frente al cine extranjero en salas colombianas:

\section{Tabla N1}

\section{Estrenos del cine nacional frente al cine} extranjero en salas colombianas

\begin{tabular}{|lllll|}
\hline Año & $\begin{array}{l}\text { Estrenos } \\
\text { colombianos }\end{array}$ & $\begin{array}{l}\text { Estrenos } \\
\text { extranjeros }\end{array}$ & Total estrenos & $\begin{array}{l}\text { Porcentaje } \\
\text { de estrenos } \\
\text { colombianos }\end{array}$ \\
\hline 1993 & 2 & 274 & 276 & $0.72 \%$ \\
\hline 1994 & 1 & 267 & 268 & $0.37 \%$ \\
\hline 1995 & 2 & 249 & 251 & 0.805 \\
\hline 1996 & 3 & 270 & 273 & $1.10 \%$ \\
\hline 1997 & 1 & 251 & 252 & $0.40 \%$ \\
\hline 1998 & 6 & 237 & 243 & $2.47 \%$ \\
\hline 1999 & 3 & No disponible & No disponible & No disponible \\
\hline 2000 & 4 & 200 & 204 & $1.96 \%$ \\
\hline 2001 & 7 & 196 & 203 & $3.45 \%$ \\
\hline 2002 & 8 & 176 & 180 & $2.22 \%$ \\
\hline 2003 & 5 & 170 & 175 & $2.86 \%$ \\
\hline 2004 & 8 & 159 & 167 & $4.79 \%$ \\
\hline 2005 & 8 & 156 & 164 & $4.88 \%$ \\
\hline 2006 & 8 & 154 & 162 & $4.94 \%$ \\
\hline
\end{tabular}

Fuente: Varios autores (2003) "Impacto del sector cinematográfico sobre la economía colombiana: situación actual y perspectivas" Fondo Mixto de Promoción Cinematográfica y Proimágenes en movimiento. P. 24

\section{ANÁLISIS DE LAS DIVERSAS CADENAS DEL PROCESO CINEMATOGRÁFICO}

\subsection{EL PROBLEMÁTICO ESCENARIO DE LA EXHIBICIÓN EN COLOMBIA}

La única parte del sector cinematográfico que ha podido sobrevivir todos estos años ha sido el de la exhibición. Desde los primeros intentos de los hermanos Di Doménico y posteriormente Cine Colombia y otras empresas, el único "negocio" de cine que ha prosperado en el país y sigue funcionando ha sido el de la exhibición.

Sin embargo, este brazo tan importante de la industria ha sido casi olvidado por la Ley y los representantes del gremio exhibicióndistribución aparentemente no le buscan solución a un problema que no es solamente colombiano sino latinoamericano. Pensar en que nuestro cine se pueda ver fuera de nuestras fronteras, así sea solamente en Latinoamérica, es una utopía ya que su exhibición no depende de calidad, interés o creatividad, sino de una crítica ausencia de salas especializadas para cine de habla hispana en toda la región. Hollywood domina más del $80 \%$ del cine que se puede ver y la única forma de contrarrestar ese fenómeno es con salas especializadas donde el cine de Hollywood estaría vetado de por vida.

En Colombia existen cinco grandes exhibidores de cine comercial en su orden: Cine Colombia, Cinemark, Procinal, Cinépolis y Royal Films además de varios exhibidores independientes dentro de los que se destacan Babilla Cine, la Cinemateca Distrital de Bogotá, la sala de cine Los Acevedos del Museo de Arte Moderno de Bogotá y el Cine Club El Muro (Bogotá).

Es pertinente a continuación hacer una revisión de las estadísticas de la exhibición en Colombia. 
Tabla N 2

Estadísticas de la exhibición en Colombia - 2009

\begin{tabular}{|c|c|c|c|c|c|}
\hline EXHIBIDOR & $\begin{array}{c}\text { Comple- } \\
\text { jos }\end{array}$ & Salas & Sillas & $\begin{array}{l}\text { Participa- } \\
\text { ción Com- } \\
\text { plejos }\end{array}$ & $\begin{array}{c}\text { Partici- } \\
\text { pación } \\
\text { Salas }\end{array}$ \\
\hline $\begin{array}{l}\text { Cine Colom- } \\
\text { bia S.A }\end{array}$ & 37 & 204 & 45.272 & $20 \%$ & $34 \%$ \\
\hline $\begin{array}{l}\text { Cinemark } \\
\text { Colombia } \\
\text { S.A. }\end{array}$ & 10 & 60 & 13.711 & $5 \%$ & $10 \%$ \\
\hline Procinal & 17 & 74 & 11.223 & $9 \%$ & $12 \%$ \\
\hline $\begin{array}{l}\text { Royal Films } \\
\text { Ltda }\end{array}$ & 22 & 83 & 14.969 & $12 \%$ & $14 \%$ \\
\hline $\begin{array}{l}\text { Otros (76 } \\
\text { exhibidores) }\end{array}$ & 96 & 172 & 38.377 & $53 \%$ & $29 \%$ \\
\hline Totales & 182 & 593 & 123.552 & $100 \%$ & $100 \%$ \\
\hline
\end{tabular}

Salas por

ciudades

\begin{tabular}{|l|c|c|c|c|c|}
\hline \multicolumn{1}{|c}{ CIUDAD } & $\begin{array}{c}\text { Com- } \\
\text { plejos }\end{array}$ & Salas & Sillas & $\begin{array}{c}\text { Participa- } \\
\text { ción Com- } \\
\text { plejos }\end{array}$ & $\begin{array}{c}\text { Partici- } \\
\text { pación } \\
\text { Salas }\end{array}$ \\
$\begin{array}{l}\text { BARRANQUI- } \\
\text { LLA }\end{array}$ & 11 & 37 & 9.639 & $6 \%$ & $6 \%$ \\
$\begin{array}{l}\text { BOGOTÁ } \\
\text { CALI }\end{array}$ & 60 & 238 & 50.907 & $33 \%$ & $40 \%$ \\
MEDELLIN & 14 & 59 & 11.603 & $8 \%$ & $10 \%$ \\
$\begin{array}{l}\text { OTROS (39 } \\
\text { municipios) }\end{array}$ & 19 & 71 & 14.474 & $10 \%$ & $12 \%$ \\
Totales & 78 & 188 & 36.929 & $43 \%$ & $32 \%$ \\
\hline
\end{tabular}

El exhibidor con mayor presencia es Cine Colombia (34\%), seguido de Royal Films (14\%), Procinal $(12 \%)$ y Cinemark $(10 \%)$. Para el director y libretista Julio Luzardo, la exhibición no es sólo un negocio, también es un derecho que el Estado debería proteger y promover.

"Todos los países que impusieron cuotas y restricciones al cine norteamericano vieron crecer sus cinematografías nacionales y su público exponencial y sostenidamente. Sólo un circuito independiente, de cobertura nacional, formador de espectadores, que no responda a intereses foráneos, patrocinado por el Estado, donde las películas puedan tener poco público, sin que las expulsen arbitrariamente de las salas, estableciendo otro tipo de relación con aquellos que las ven, más allá del mercadeo imperante, se impone como una necesidad absoluta".

El Estado debería garantizar ese derecho a través de la Ley de Cine, inherente a la identidad nacional.

\section{OPTIMISTAS $Y$ PESIMISTAS} FRENTE A LOS EFECTOS DE LA LEY DEL CINE

En 2004 la producción colombiana ascendió a 16 películas entre ellas dos óperas primas y durante 2005 se estrenaron cintas como 'Perder es cuestión de método', de Sergio Cabrera y 'La sombra del caminante', de Ciro Guerra.

a omp

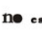

$\mathbf{f a ́}_{\mathbf{c} \mathbf{i} \mathbf{1}}$

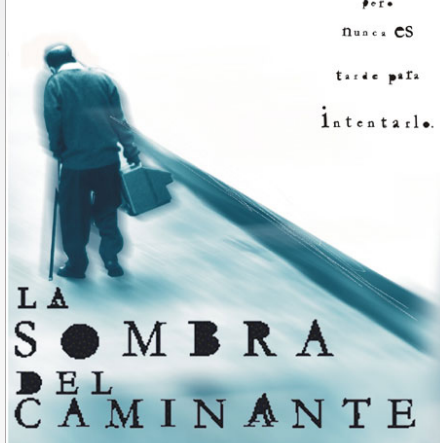


Según Claudia Triana, gestora y promotora del cine colombiano, son muchas las expectativas que se han generado en torno a la Ley de Cine, pero no hay que olvidar que desde el nacimiento de la Dirección de Cinematografía se han generado estímulos financieros que han permitido apoyar entre tres y cuatro largometrajes por año. También es importante resaltar que algunos directores y productores se están profesionalizando, no están atados a los recursos estatales, están buscando coproducciones en el exterior, como "María llena eres de gracia" que no recibió estímulo del gobierno y sin embargo fue una película que le hizo mucho bien al cine colombiano. Lo que tradicionalmente buscan las películas de autor, que son los recursos estatales y ayudas tributarias.

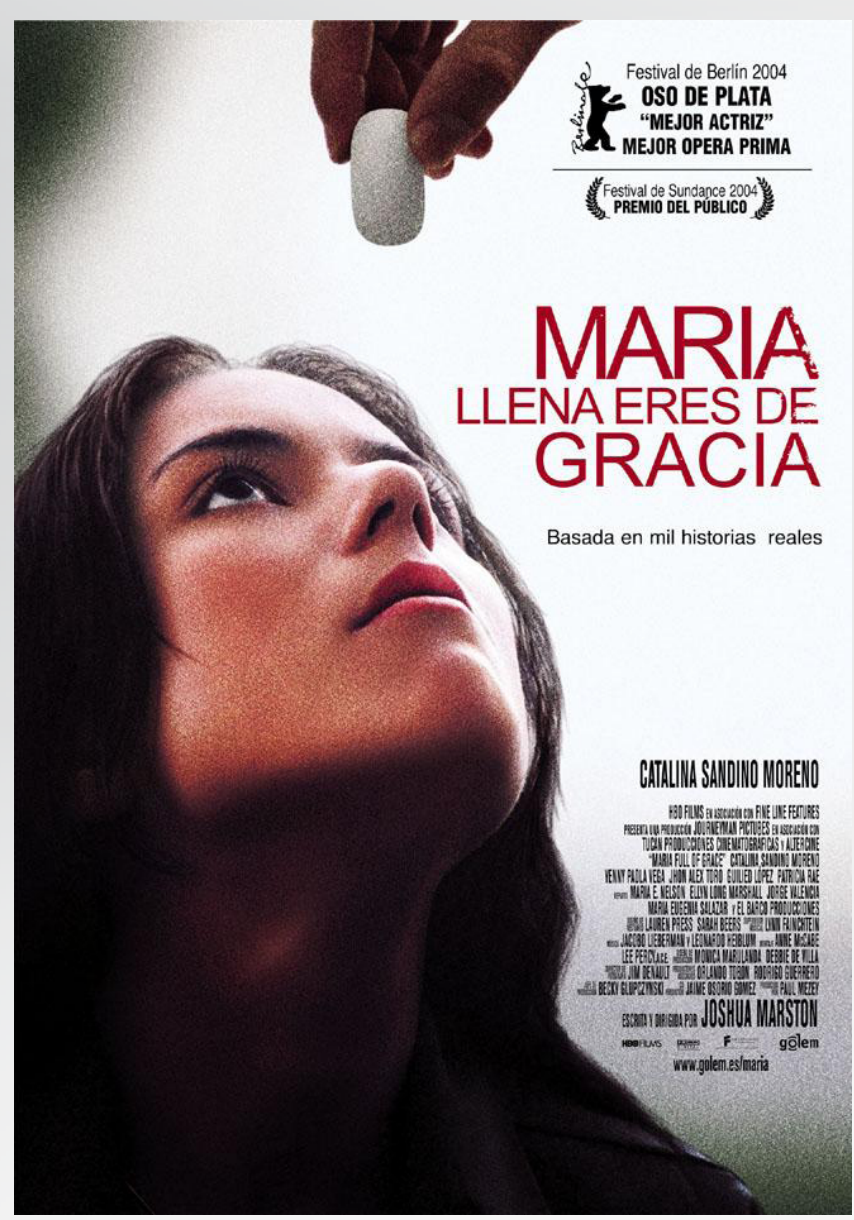

"en el 2005, sólo siete de las 20 películas que se realizaron, recibieron dineros de la Dirección, las demás, gestionaron capitales privados o fueron coproducciones internacionales como "Rosario Tijeras" y "Perder es cuestión de método". Esto significa que hay una excelente atmósfera para trabajar, la gente está entusiasmada en contar sus historias, en lanzarse, dice Claudia Triana.

Los pesimistas se preguntan ¿Se ha alcanzado el espíritu de la Ley? $\mathrm{O}$ ¿El espíritu de la Ley es letra muerta por las deficiencias de un sistema que no funciona como se esperaba?

La idea general detrás de la Ley de Cine fue proveer los mecanismos necesarios para establecer bases sólidas para un negocio que lleva casi 100 años en el país y que hasta el día de hoy no ha logrado establecerse como "industria" y ha sido la responsable de innumerables quiebras individuales y de empresas que han creído en el sueño imposible de una cinematografía nacional. Sencillamente no se puede seguir con esta filosofía de creer que el cine nacional está bien simplemente porque se está produciendo más que nunca. ¿Y qué ha pasado con las ganancias que debe generar cualquier negocio, el retorno que le debe generar a un inversionista que ha creído en los beneficios de la Ley más allá de ser un simple ahorro en impuestos y todas las otras incógnitas que han aparecido y que demuestran que seguimos igual o peor que antes de la Ley?

En el artículo titulado "¿Será 2005 el año del cine colombiano?" [2] Sergio Villamizar señaló que, a pesar de que ese año se exhibieron 18 películas colombianas, 10 más que en el 2004, había una fuerte preocupación porque pese a la apertura de nuevos multiplex de parte de Cine Colombia, Royals Films y Cinemark, no se había 
podido superar la cifra más alta de 18 millones de espectadores de 2003, cifra en la que están incluidos los espectadores a películas extranjeras y colombianas.

La inquietud que alude Villamizar es que los productores y realizadores de estos largometrajes nacionales compiten en enorme desventaja con más de 250 largometrajes hollywodense anualmente.

Desde que se implementó la Ley 814, hace casi seis años, se han exhibido cincuenta (50) largometrajes colombianos en las salas de cine del país. El $90 \%$ de estos largometrajes han recibido auxilios directos del Fondo de Cinematografía y de Ibermedia, las películas las han visto casi 11 millones de espectadores en Colombia y le han dejado un poco más de $\$ 34$ mil millones de pesos a sus productores en premios y resultados de taquilla en Colombia después de descontar televisión, publicidad, exhibición, distribución e impuestos. Sin embargo, estas mismas películas costaron más o menos $\$ 65$ mil millones producirlas y en el conteo final las cifras son francamente aterradoras: del costo de inversión, sólo se recuperó un $52.76 \%$, las pérdidas fueron alrededor del $47.24 \%$ y 42 películas ni siquiera lograron recuperar su costo de inversión.

Una de las voces más críticas de la Ley de cine 814 de 2003, Julio Luzardo, plantea fuertes observaciones en su artículo "Diez sugestivas para enderezar el camino. Para donde va la Ley del cine" [3].

"El cine colombiano siempre ha tenido estos mismos resultados negativos a través de su historia desde 1922 cuando se estrenó La María. Nuestro cine ha sido una serie de intentos individuales, artesanales, de hacer cine contra viento y marea. $Y$ hoy en día, a pesar de tener una flamante Ley de Cine que se suponía iba a romper la historia en dos, seguimos igual o peor que antes".

En un dossier especial de la revista Kinetoscopio, un funcionario del sector monopólico de la distribución y la exhibición de cine afirmaba que el mercado, en los términos practicados por dicha empresa, no aguantaba diez películas colombianas de manera simultánea en pantalla. $Y$ vaticinaba:

«el día que se empiecen a hacer veinte o veinticinco películas (colombianas) al año, nos reventamos» (sic). Palabras más, palabras menos, el público cinematográfico es, según los intereses defendidos por esta compañía, una invención estadounidense $y$, por ende, se debe a las películas norteamericanas. Triste argumento.

Si el aumento en la producción no tiene ninguna incidencia en el aumento del público, y sí, contradictoriamente, en su disminución, y frente al hecho de que más películas realizadas en Colombia se pelean un número cada vez más pequeño de espectadores, cabría preguntarse: ¿qué, cómo y para quién estamos produciendo?

Para los entrevistados hacen falta más investigaciones y bases de datos. El Consejo de Cinematografía debería desarrollar un análisis riguroso y detallado de la situación económica actual del cine colombiano. Nuevamente Luzardo:

"En este momento, a través del sistema computarizado CIREC, el Consejo $y$ Proimágenes, como nunca antes en la historia del cine colombiano, tienen acceso a toda la información detallada de entrada de público a todas las salas cinematográficas del país y no han sido capaces sino de sacar algunos datos 
de taquillas de las primeras semanas de algunas de las últimas películas colombianas en su Boletín semanal Pantalla Colombia. Estos pocos datos sueltos y sin continuidad o evaluación, a la larga no sirven de mucho porque no son sino cifras aisladas sin ningún análisis de fondo".

\section{CONCLUSIONES}

¿Qué grandes fracasos refleja la Ley de cine? Desde el pesimismo hay acuerdo: no hemos salido de la parroquia. Si queremos internacionalizar nuestro cine, es necesario enfocar la mirada a la búsqueda de mercados externos a través de cuatro líneas: a) Fondos Internacionales, b) Coproducciones, c) Ventas en el exterior; d) Comisión Fílmica (para atraer rodajes extranjeros al país)

Para consolidar el punto anterior sobre la internacionalización del cine nacional, habría que también reforzar urgentemente el mundo de los guionistas en Colombia, a través de un proceso riguroso de selección de los guiones de mayor calidad, ofreciendo alternativas de financiamiento e incentivando su distribución internacional. Es urgente desmarcarse de la telenovelización del cine colombiano, es decir, de formas particulares de relatar y narra nuestras realidades, para así asumir nuevas y atractivas historias en clave de lenguaje cinematográfico, con el fin de capturar a un mayor mercado potencial de espectadores. Se trata, en suma, de ofertar miradas y producciones innovadoras, estéticamente sugestivas, con guiones mejor elaborados

La apuesta por la formación de públicos es un imperativo categórico, pero no es posible de diseñar, formalizar y ejecutar si no se articula con la formación de lectores, y eso es un problema de política educativa unida a política cultural
La función de administrador del fondo a través de un organismo mixto debería virar claramente hacia el acompañamiento posterior y permanente a la entrega del apoyo en todas sus etapas. $\mathrm{Si}$ bien Proimágenes representa los derechos del cine colombiano en casi todo su conjunto, eso no significa que esté distribuyéndolo activamente en los mercados internos y foráneos de manera permanente, o que suscriba acuerdos activos de coproducción o distribución con otros países u organismos pares. No hay una clara política estatal de apoyo a la distribución y a la coproducción, ni un generador de estadísticas independientes, confiables y comparativas que permita trazar líneas de acción ajustadas a la realidad cambiante del mercado, para diseñar políticas de Estado sostenibles a largo plazo, tendientes a la creación de una industria sustentada en un fuerte mercado interno.

Los criterios de formulación de largometrajes evidencian que los proyectos presentados a convocatorias de largometrajes no saben formular y diseñar presupuestos con "sentido de realidad". Y el acto de ser creadores y artistas requiere todo un proceso de formalización y sistematización rigurosa.

\section{BIBLIOGRAFÍA}

CEDEM (2001), Las industrias culturales. Situación actual y potencialidades para su desarrollo, en "Coyuntura Económica de la Ciudad de Buenos Aires", №. 2, Secretaría de Desarrollo Económico, Gobierno de Buenos Aires.

CONVENIO ANDRÉS BELLO (2003), "Impacto del sector cinematográfico sobre la economía colombiana: situación actual y perspectivas," Bogotá.

FEDESARROLLO. Cuadernos $\mathrm{N}^{\circ} 50$ "Impacto económicodelsectorcinematográficocolombiano". No. 50. Tomado de: http://www.fedesarrollo.org. co/contenido/capitulo.asp?chapter $=186$ 
GETINO, O (2006), Las Industrias Culturales del Mercosur, Observatorio de Industrias Culturales Buenos Aires.

LUZARDO, Julio (2009) "Para donde va la ley del cine" en www.enrodaje.com

MONETA, C. J (2000), Cultural Industries in the Latin American economy: current status and outlook in the context of globalization, Office of Cultural Affairs OAS/OEA

O'CONNOR, J (1999)., The Definition of 'Cultural Industries', Manchester Institute for Popular Culture Manchester Metropolitan University.

SAFIR, Lawrence (2004) From distribution to exhibition: Bringing Films to movie theatres. Afma Europa. Roma

VARIOS AUTORES (2003) "Impacto del sector cinematográfico sobre la economía colombiana: situación actual y perspectivas" Fondo Mixto Promoción Cinematográfica y Proimágenes en movimiento.

\section{NOTAS}

[1] Este artículo es uno de las reflexiones producto de la investigación "La ley 814 de 2003 ¿podrá despegar la industria cinematográfica colombiana? financiado por la Dirección de Investigaciones de la Universidad Nacional de Colombia, sede Manizales- DIMA.

[2] http://www.latinoamerica-online.info/cult05/cine05.02.html

\section{Para citar este artículo:}

D’abbraccio, G. (2015). La industria del cine Colombia. Entre el optimismo ingenuo y el pesimismo crónico. Revista Luciérnaga/ Comunicación, Año 7, N14. Facultad de Comunicación AudiovisualPolitécnico Colombiano Jaime Isaza Cadavid-PCJIC \& Facultad de Ciencias de la Comunicación -

Universidad Autónoma de San Luis Potosí- UASLP. México. Págs. 36-45.

\section{DOI. 10.33571/revistaluciernaga.v7n14a1}

